\title{
Using Animated Pedagogical Agents in Introductory Object Oriented Programming Concept (Java)
}

\author{
Adib Sarkawi, Aiza Johari, Adeline Engkamat, and Ketty Chachil
}

\begin{abstract}
Teaching the concept of object oriented programming in Java to beginner students may pose to be challenging. As a result, this paper explores how a tutoring online multimedia learning application aided by animated pedagogical agents can aid the learning of Introductory Object Oriented Programming Concept (OOP-Concept) in Java in which the users' satisfactions in operating the developed animated pedagogical agents were examined. An adapted questionnaire was distributed to thirty Semester 2 Computer Science Diploma students of University Technology Mara Sarawak, Malaysia right after the running session. The general findings revealed that most users were satisfied in using multimedia application with the existence of APA agents to learn OOP-Concept. Their satisfactions resulting from this study are able to be a stepping point for developing a better multimedia learning.
\end{abstract}

Index Terms-Animated pedagogical agents, multimedia application.

\section{INTRODUCTION}

Animated Pedagogical Agents (APA) offer great promise for learning environments. The intriguing lifelike characters often allow users to interact with the agents; hence they play important pedagogical roles. According to Mayer's Cognitive Theory of Multimedia learning in Unal-Colak and Ozan (2012), APA improve learning by facilitating computer-human's social interaction and transmitting non-verbal implicit information. As APA are believed to enhance JAVA learning, this paper aims to evaluate the users' satisfactions in utilising multimedia learning application combined with APA to aid Object Oriented Programming Concept (OOP-Concept) learning.

\section{RESEARCH METHOD}

The subjects were 30 Semester 2 Object Oriented Programming students from Computer Science Diploma

Faculty in University Technology Mara Sarawak, Malaysia. The topic chosen for the application was Chapter 2 of OOP

Concept I- CSC175 subject (Introduction of Class, Encapsulation, Inheritance and Polymorphism).

Manuscript received February 13, 2013; revised June 2, 2013.

Adib Sarkawi and Ketty Chachil are with University Technology MARA, 94300, Sarawak, Malaysia (e-mail: adib@sarawak.uitm.edu.my, ketty@sarawak.uitm.edu.my).

Aiza Johari and Adeline Engkamat are with University Technology MARA, 94300, Sarawak, Malaysia (e-mail: aiza@sarawak.uitm.edu.my, adelineeng@sarawak.uitm.edu.my).
First, the researchers developed online multimedia learning application by using a variety of multimedia elements (text, graphic, audio and animations) and the application was created with APA implementation. The application consists of modules related to OOP-Concept topic.

According to Doll and Torkzadeh (1988) in Xiao and Dasgupta (2004), there are five components to test user satisfaction with computer applications: content, accuracy, format, ease of use and timeliness. The users' satisfactions for this research were assessed based on one indicator: users' satisfactions towards tutoring application with APA as a whole (Content, Ease of Use, Format, Accuracy and Satisfaction with Animated Pedagogical Agents).

The questionnaire has two sections: students' profiles and their perceptions towards OOP - Concept Prototype Application (the five constructs above). The respondents were asked to complete the questionnaire adapted from Chin and Lee's End-User Computing Satisfaction questionnaire (2000) and Lester, Converse, Kahler, Barlow, Stone and Bhogals's System and Agent Assessment questions (1997), after they had learned to use the developed application. The data then was analyzed using SPSS Version 20 based on the frequency count and mean score.

\section{DAta ANALYsis}

\section{A. Demographic Data}

Demographic data reveals CSC125 subject results (achieved from previous semester) and OOP-Concept Background. This subject is the foundation to programming language and should be taken by the respondents during Semester One. It is apparent that half of the respondents' competences in Basic Programming Language ranged from excellent to average with $13 \%$ of the respondents obtaining Grade A, 10\% Grade A-, $17 \%$ Grade B+ and 10\% grade B. Another half of the respondents were at average level with $13 \%$ of the respondents getting Grade B-, 20\% Grade C+ and another $17 \%$ Grade C. As a result, CSC125 results had given a general view of their knowledge regarding programming language.

In relevance to the respondents' OOP-Concept knowledge, assumably, most respondents had 'good' knowledge with the percentage of $53 \%$, followed by $27 \%$ the respondents who had 'average' knowledge on the related topic. Another 13\% of the respondents had 'beginner' understanding and 7\% had 'excellent' knowledge in OOP-Concept. These indicate that most of the respondents obtained basic knowledge in the Concept. As a consequence, during the satisfaction 
evaluation, the respondents were able to focus on the application (particularly on APA).

\section{B. Evaluation of the Users' Satisfactions}

The survey indicated the respondents' perceptions and expectation evaluations toward the tutoring application with the guidance of the developed APA in learning OOP-Concept (content, accuracy, format, ease of use and animated pedagogical agents).

\section{1) Content}

This section discusses the content within the OOP-Concept application with APA (the respondents' satisfaction level for precision and the amount of information provided).

TABLE I: PERCENTAGE OF THE RESPONDENTS: APPLICATION's CONTENT

\begin{tabular}{|c|c|c|c|c|c|c|}
\hline \multicolumn{7}{|c|}{ WITH APA } \\
\hline & $\mathrm{AN}$ & ST & AHT & MT & AA & MS \\
\hline & $\%$ & $\%$ & $\%$ & $\%$ & $\%$ & \\
\hline Precise info & .0 & .0 & 13.3 & 66.7 & 20.0 & 4.07 \\
\hline $\begin{array}{l}\text { Right amount } \\
\text { of info }\end{array}$ & .0 & .0 & 30.0 & 43.3 & 26.7 & 3.97 \\
\hline $\begin{array}{l}\text { Content meet } \\
\text { your needs }\end{array}$ & .0 & .0 & 23.3 & 60.0 & 16.7 & 3.93 \\
\hline $\begin{array}{l}\text { Right amount } \\
\text { of info }\end{array}$ & 3.3 & .0 & 26.7 & 56.7 & 13.3 & 3.77 \\
\hline Sufficient info & 3.3 & $\begin{array}{c}10 . \\
0\end{array}$ & 30.0 & 46.7 & 10.0 & 3.50 \\
\hline
\end{tabular}

Overall Mean 3.83

AT: Almost Never, ST : Some Of The Time, AHT : About Half Of The Time, MT : Most Of The Time, AA : Almost Always, MS : Mean Score

More than half of the respondents $(66.7 \%)$ agreed that most of the time, the OOP-Concept application with the existence of APA was able to provide precise information while the mean score of 4.07 further confirmed the fact that the application provides precise information. Another $60 \%$ admitted that the content met their needs most of the time. Similarly, the mean score of 3.93 also revealed that the respondents admitted that the application content has matched their expectations. To add, more than half of the respondents claimed that the application gave the right amount of information which met their needs most of the time while $13.3 \%$ 'almost always'.

\section{2) Accuracy}

This section focuses on the accuracy of the application and information provided within OOP-Concept application with APA.

Overall, $46.7 \%$ of the respondents agreed that most of the time, they were satisfied with the accuracy of the application provided by the application. To add, $63.3 \%$ of the respondents were 'most of the time' agreed that the application provides correct information while another $33.3 \%$ of the respondents were 'always almost'. Likewise, looking at the mean score of 4.27 (beyond the average mean score), it represents overall agreements from most of the respondents where they acknowledged the correctness of information in OOP-Concept application. Besides, another $80 \%$ of the respondents were 'most of the time' satisfied with the idea of the application providing reliable information. The overall mean score for accuracy construct was 3.92 which confirmed that the application was at an exceptional level of satisfaction (in terms of application accuracy).

TABLE II: PERCENTAGE OF THE RESPONDENTS: APPLICATION’S ACCURACY

\begin{tabular}{lcccccc}
\multicolumn{7}{c}{ WITH APA } \\
& AN & ST & AHT & MT & AA & MS \\
\cline { 2 - 7 } & $\%$ & $\%$ & $\%$ & $\%$ & $\%$ & \\
& .0 & .0 & 13.3 & 46.7 & 40.0 & 4.27 \\
$\begin{array}{l}\text { Satisfaction - } \\
\begin{array}{l}\text { Accurate } \\
\text { application }\end{array}\end{array}$ & & & & & & \\
$\begin{array}{l}\text { Provide correct } \\
\text { information }\end{array}$ & .0 & 3.3 & .0 & 63.3 & 33.3 & 4.27 \\
$\begin{array}{l}\text { Provide reliable } \\
\text { information }\end{array}$ & .0 & .0 & .0 & 80.0 & 20.0 & 4.2 \\
$\begin{array}{l}\text { Dependable } \\
\begin{array}{l}\text { Accurate } \\
\text { Application }\end{array}\end{array}$ & .0 & .0 & 26.7 & 63.3 & 10.0 & 3.83 \\
$\begin{array}{l}\text { Error free } \\
\text { Overall Mean }\end{array}$ & 3.3 & 23.3 & 26.7 & 33.3 & 13.3 & 3.3 \\
\hline
\end{tabular}

AT: Almost Never, ST : Some Of The Time, AHT : About Half Of The Time, MT : Most Of The Time, AA : Almost Always, MS : Mean Score

\section{3) Format}

This section examines the format or the arrangement of information as well as the output format provided within the OOP-Concept application (the arrangement and layout of the information with APA).

TABLE III: PERCENTAGE OF THE RESPONDENTS: APPLICATION'S FORMAT WITH APA

\begin{tabular}{|c|c|c|c|c|c|c|}
\hline & $\overline{\mathrm{AT}}$ & ST & AHT & MT & AA & MS \\
\hline & $\%$ & $\%$ & $\%$ & $\%$ & $\%$ & \\
\hline $\begin{array}{l}\text { Satisfaction - } \\
\text { layout }\end{array}$ & 3.3 & .0 & 26.7 & 23.3 & 46.7 & 4.10 \\
\hline Clear & .0 & 6.7 & 10.0 & 53.3 & 30.0 & 4.07 \\
\hline $\begin{array}{l}\text { Satisfaction - } \\
\text { presented } \\
\text { info }\end{array}$ & .0 & .0 & 20.0 & 53.3 & 26.7 & 4.07 \\
\hline Useful format & .0 & 6.7 & 10.0 & 66.7 & 16.7 & 3.93 \\
\hline $\begin{array}{l}\text { Satisfaction - } \\
\text { output format }\end{array}$ & .0 & $.0 \%$ & 30.0 & 46.7 & 23.3 & 3.93 \\
\hline Overall Mean & \multicolumn{6}{|c|}{4.02} \\
\hline
\end{tabular}

It is apparent that the information provided by OOP-Concept is clear and understandable as $53.3 \%$ of the respondents frequently felt that the information provided in the application was clear. When asked whether they were satisfied with the way the information was presented, it reveals that most of the respondents chose 'most of the time' with the percentage of $53.3 \%$, followed by $26.7 \%$ of the respondents 'almost always'. These are encouraging as obviously they were generally satisfied with the arrangement and output format of the information delivery. Another excellent satisfaction levels are illustrated where most of the respondents $(46.7 \%)$ were 'most of the time' satisfied with the format of the output. In addition, none of the respondent opted 'almost never' and 'some of the time' in which strengthen the encouraging results. The overall mean score of 4.02 also shows exceptional satisfactory level thus the format features in the application are usable and helpful, specifically with the appearances of the animated pedagogical agents. 


\section{4) Ease of use}

This section depicts the respondents' satisfaction levels and expectations toward the user-friendliness and effort required to utilize the provided OOP-Concept application with APA.

TABLE IV: PERCENTAGE OF THE RESPONDENTS: APPLICATION'S EASE OF

\begin{tabular}{|c|c|c|c|c|c|c|}
\hline \multicolumn{7}{|c|}{ USE WITH APA } \\
\hline & AT & $\mathrm{ST}$ & AHT & MT & AA & MS \\
\hline & $\%$ & $\%$ & $\%$ & $\%$ & $\%$ & \\
\hline Easy to use & .0 & .0 & 13.3 & 33.3 & 53.3 & 4.40 \\
\hline Easy to operate & .0 & .0 & .0 & 66.7 & 33.3 & 4.33 \\
\hline $\begin{array}{l}\text { Easy to get } \\
\text { application to } \\
\text { do what you } \\
\text { want it to do }\end{array}$ & .0 & .0 & 20.0 & 30.0 & 50.0 & 4.30 \\
\hline Easy to interact & .0 & .0 & 10.0 & 66.7 & 23.3 & 4.13 \\
\hline $\begin{array}{l}\text { Clear and } \\
\text { understandable } \\
\text { interaction }\end{array}$ & .0 & 6.7 & 30.0 & 56.7 & 6.7 & 3.63 \\
\hline Overall Mean & & & & 16 & & \\
\hline
\end{tabular}

AT: Almost Never, ST : Some Of The Time, AHT : About Half Of The

Time, MT : Most Of The Time, AA : Almost Always, MS : Mean Score

It is evident that $53.3 \%$ of the respondents felt that 'almost always' the developed application was accessible while $33.3 \%$ with 'most of the time'. Besides that, another positive indicator shows that $66.7 \%$ of the respondents 'most of the time' admitted that it was easy to operate the application, followed by $33.3 \%$ with 'almost always'. Next, $56.7 \%$ of the respondents agreed that 'most of the time' the interaction with the application was clear and understandable. These outcomes are promising because they show that APA do play important roles as the added features can contribute to users' satisfaction levels in the context of application's ease of use. Notably, the mean score of 4.16 presented supportive evidence that OOP-Concept is easy to use and interactive, especially when the animated pedagogical agents are uncomplicated and meaningful.

\section{Animated Pedagogical Agents (APA)}

This section discusses the mode of the respondents' satisfactions and expectations with the developed APA during the OOP-Concept application.

\section{Mean Scores of Respondent towards APA}

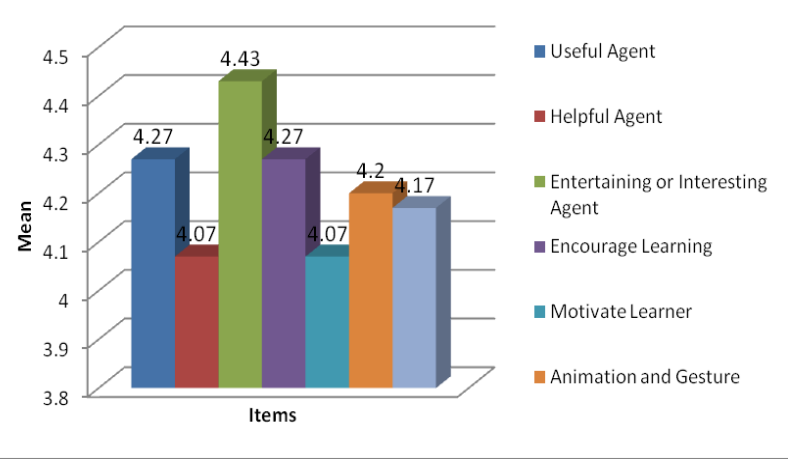

Fig. 1. Mean scores of respondents towards APA.

Overall, all mean scores are above average, indicating fine scores. Exceptional mean scores from three items state that the agents were useful (4.27), encouraging (4.27) and entertaining (4.43). These support the findings from a research conducted by Hanafi, Foo, Baharudin, Wong, Omar and Zuraidah (2008), where their respondents claimed that the agents provided more fun, interesting, informative and motivating learning.

The other items have also gained good mean scores which are 4.07 (Helpful Agent), 4.07 (Motivate Leaner), 4.2 (Animation and Gesture) and 4.17 (Text - To - Speech). These mean scores are able to be support the facts that most of the respondents were satisfied with the agents, which can give positive impacts in learning (with the aid of adapted agents within the multimedia application). Johnson and Rickel (1998) affirmed that the ability of an agent is to have enough understanding of the learning context and subject matter so that they are able to perform useful roles in learning scenarios.

Moreover, the APA are capable of explaining verbal output where many of the respondents felt that listening to the explanation can increase their understanding compared to mere reading. The APA also offer hints during question-answer session and at the same time allow users to think critically to get the answer needed. Baylor and Kim (2004) asserted that by manipulating an interface agent's image, it can significantly enhance learner motivation with a large effect. Furthermore, Moniri (2006) claimed that an agent with rich repertoire of emotive behaviors to exhibit contextually appropriate facial expression and expressive gestures will allow the animated pedagogical agents to exploit the visual channel to advise, encourage and motivate students. As further suggested by Veletsianos (2007), the agents' contextual relevance and aesthetic properties need to be considered to fully utilise their potentials, as the anthropomorphous features and social affordances of the APA can elicit psychological responses from the learners that other media cannot extract. To sum, the overall results from the findings disclose that a multimedia application supplemented with animated pedagogical agents can bring useful transformations in the learning environment.

\section{REFERENCES}

[1] F. Unal-Colak and O. Ozan. (April 2012). The Effects of Animated Agents on Students' Achievement and Attitudes. Turkish Online Journal of Distance Education. [Online]. 13(2). pp. 2. Available: http://tojde.anadolu.edu.tr/tojde47/article_2.htm

[2] L. Xiao and S. Dasgupta, "Measurement of User Satisfaction with Web-Based Information Systems: An Empirical Study," Eight Americas Conference on Information Systems, 2004.

[3] W. W. Chin and M. K. Lee, "A Proposed Model and Measurement Instrument for the Formation of IS Satisfaction: The Case of End-User Computing Satisfaction," presented at the Twenty - First International Conference on Information Systems, 2000.

[4] C. J. Lester, S. A Converse, S. E. Kahler, S. T. Barlow, B. A. Stone, and R. S. Bhogals, "The Persona Effect: Affective Impact of Animated Pedagogical Agents," in Proc. CHI. 97, pp. 359 - 414, 1997.

[5] A. Hanafi, K. A. K. Foo, L. Baharudin, M. S. Woo, M. Omar, and R. A. Zuraidah, "The Different Roles of Pedagogical Agents in the Open Source Learning Management System," presented at Conference of Excellence in Education 2008, France, 2008

[6] W. L. Johnson and J. Rickel, "Steve: An Animated Pedagogical Agent for Procedural Training in Virtual Environments." SIGART Bulletin, vol. 8, pp.16-21, 1998.

[7] A. L. Baylor and Y. Kim, "Simulating Instructional Roles through Pedagogical Agents," International Journal of Artificial Intelligence in Education, vol. 15, 2005 
[8] M. M. Moniri. (2006). Pedagogical Virtual Characters Seminar Report. [Online]. Available: http://www.dfki.de/ kipp/ seminar/ writeups/ Mehdi_pedagogical_Agents.pdf.

[9] G. Veletsianos, "Cognitive and Affective Benefits of an Animated Pedagogical Agent: Considering Contextual Relevance and Aesthetics," Journal of Educational Computing Research, vol. 36, no. 4, pp. 373-377, 2007.

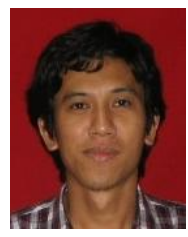

Adib Sarkawi is currently attached to University Technology MARA, Sarawak Campus in the state of Sarawak, Malaysia. He is a lecturer under the Faculty of Computer Science, teaching Diploma and Degree students. He obtained his Masters in Computer Science (Honours) from University Technology MARA Malaysia in 2008. His major field of study is Multimedia System while his areas of interests are Online Information System, JAVA Programming and Multimedia Application. 